\title{
Production Of Electronic Consumer Goods
}

Dean R. Manna, Robert Morris University, USA

\begin{abstract}
All organizations, whether they are involved in the creation of goods or services, perform three functions that are necessary for the organization's survival. These three functions are finance/accounting, marketing, and production/operations. This paper will focus on contributions that each of these three functions would make for a producer of electronic production/operations and on consumer goods. An area that has become increasingly important to a company's success is E-commerce. The Internet has revolutionized how an organization can operate with regards to its interaction with customers and suppliers.
\end{abstract}

Keywords: Design of Goods, Managing Quality, Process Strategy, Inventory Management, E-Commerce

\section{INTRODUCTION}

\begin{abstract}
$\mathrm{t}$ is widely believed that sales are the measuring stick of how well an organization is faring, but it is no secret that operations are the backbone. Operations management is a complex and detailed process that not only supplies the customer with a specific good or service, but also provides salespeople with something to sell and marketing people with something to advertise.
\end{abstract}

\section{Production/Operations}

While new products are based on a specific market need and initial forecasts are provided through sales projections and market surveys; new product development is often centered in the operational end of an organization. During the process of new product development, operations managers, regardless of product type or classification must employ all ten operations management strategy decisions of which include, "Design of Goods, Managing Quality, Process Strategy, Location Strategy, Layout Strategy, Human Resources, Supply Chain Management, Inventory Management, Scheduling and Maintenance." $\{$ Heizer and Render, pp7.\} This section will follow new product development through each of these ten steps.

\section{Design of Goods}

The main objective of design of goods in new product development is to create a product that differentiates itself and supports a competitive advantage for the company. "This competitive advantage can be obtained through differentiation, low cost, rapid response or some combination of the three." $\{$ Heizer and Render, pp. 156\}

New products are generated because older, obsolete products die off or are discontinued. Firms tend to generate the majority of their revenue and profit from new products and therefore, the design of goods being produced must be an on-going process.

Brainstorming is one method used to create new product ideas; "it is a team technique used to generate creative ideas on a particular subject. Ideas are not reviewed until after the brainstorming session." \{Heizer and Render, pp.158\} Brainstorming is often used in various stages of new product development, but always focuses on a specific opportunity, such as: \{Heizer and Render, pp.159\}

1. Understanding the customer - "the premier issue in new product development."

2. Economic change - "brings increasing levels of affluence in the long run but economic cycles and price change in the short run." 
3. Sociological and demographic change - "may appear in such factors as decreasing family."

4. Technological change - "makes possible everything from hand-held computers to cellular phones to artificial hearts."

5. Political/legal change - "brings about new trade agreements, tariffs and government contract requirements."

\section{Managing Quality}

An increasingly important portion of operations management is managing quality. Quality is the ability of a product or service to meet customer needs and it can have an impact on an entire organization. Quality is manufacturing based and in today's quality conscience workplace, an imperative part of new product development.

In addition to being a critical part of operations, quality can have a number of other implications; a company's reputation for quality, whether it is good or bad, will follow that company. "Quality will show up in the perceptions about the firm's new products, employment practices and supplier relations; and self-promotion is not a substitute for quality." \{Heizer and Render, pp.191\}

The failure of a corporation to implement a quality management system can lead to a number of additional costs that could prove to be detrimental to the company's reputation and bottom line. Included in these costs are prevention costs, which are linked to reducing the potential for defective parts or services through training or quality improvement programs. Appraisal costs, which are, related to the inspection processes. There can be costs that result due to internal failure or the production of defective parts that result in downtime, rework or scrap. Lastly, a lack of quality management can lead to external costs, such as, rework, return of goods, liabilities and lost goodwill. These occur after a part has been delivered to a customer.

Many organizations have turned to the implementation of TQM in their everyday operation, especially in the area of product development. By using such tools as continuous improvement today's manufacturers of consumer goods continue to strive for complete customer satisfaction and operational perfection in an effort to minimize costs, while maximizing profit.

\section{Process Strategy}

One of the most important Operations Management decisions in new product development is the process strategy. There are four types of strategy that can vary widely over different industries. Firms working through new product development must determine whether their new product is a line extension or a completely new offering that requires additional processes and machinery. Once that determination has been made a process strategy can be decided upon.

The process strategy will largely depend on the type of product being offered. Low volume, high variety products such as machinery, printing or carpentry will use a process-focused strategy because they provide flexibility as the products move between processes. High volume, high variety products such as computers and electronics use a mass customization focus, which is a rapid low cost production of goods that fulfills a growing unique customer want. Large-scale products like cars, boats and motorcycles use the repetitive focus or the classic assembly line production; they have much more structure and less flexibility. Lastly, high volume and diverse products such as steel and glass are product focused or continuous processes; they have long continuous production runs.

\section{Location Strategy}

When developing a new product it is important that corporations also form a location strategy. A number of factors can affect a new products profitability and successfulness in regards to location. Everything from labor productivity to exchange rates, for foreign manufacturers, can have a dramatic impact on new products. Locating a new product near the end user to reduce shipping costs is important, it is equally important to make sure that a production facility is also close to suppliers and near necessary raw materials due to perishability and transportation costs. 


\section{Layout Strategy}

As we mentioned previously, certain operational decisions regarding new product development depend greatly on whether the product is a line extension or totally new product. Preparing a layout strategy is another example of where this issue arises. If a corporation is simply introducing a new product that is a line extension of an existing one, chances are that the basic layout is already in place. However, if the product is new to market, the operations manager must determine which of the six definitive layout strategies should be employed.

There are several different layout strategies that can be employed. The first is a fixed position layout, which "addresses the layout requirements of stationary projects or large bulky projects." The second is a processoriented layout. A process-oriented layout, "deals with low-volume, high variety production." An office layout, "groups workers and their equipment and spaces/offices to provide comfort, safety and movement of information." In retail layout the flow and the allocation of space are addressed and customer behavior is responded to quickly. Warehouse layouts are designed in an effort to "minimize total cost by addressing trade-off between space and material handling." Finally, product oriented layouts "are organized around products or families of similar highvolume, low variety products. Repetitive production and continuous production use product layouts." \{Heizer and Render, pp. 332-347.\}

\section{Human Resources}

It is the objective of all operations managers to develop an effective human resource strategy and manage labor and design jobs so employees are "effectively and efficiently utilized." In order to have productive work environment managers need to be sure that their employees are "efficiently utilized within the constraints of other operations management decisions and have a reasonable quality of work life in an atmosphere of mutual commitment and trust." \{Heizer and Render, pp.370

When developing new product it is necessary to have the appropriate people in the proper positions. A personnel failure or mistake can cost a company time, money or sales as every part of an operation feeds into the corporate human resource strategy as seen in the diagram below.

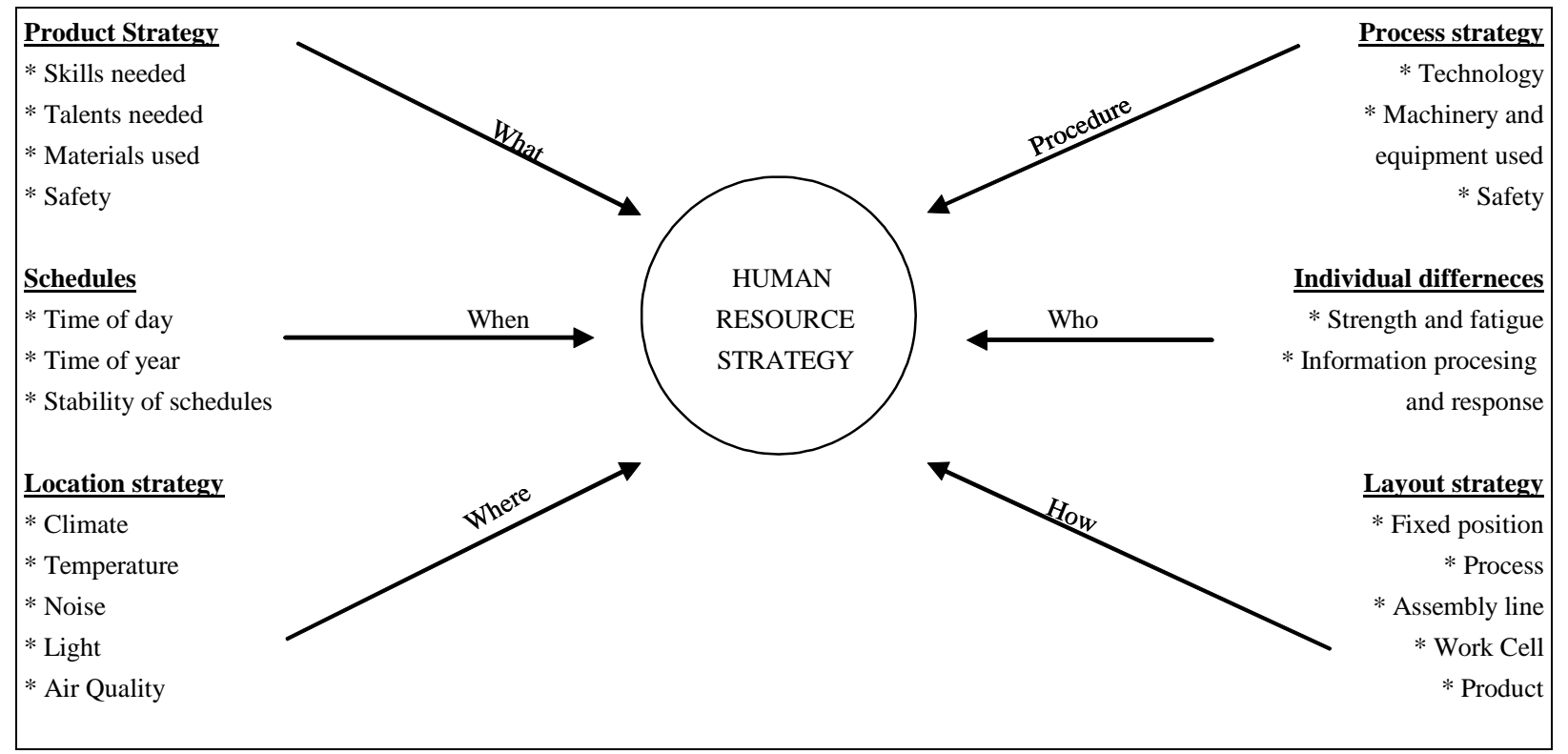

Figure 10.1: Heizer and Render, pp.371 


\section{Supply Chain Management}

Supply chain management is "the integration of the activities that procure materials and services, transform them into intermediate goods and final products and deliver them to customers." \{Heizer and Render, pp. 414\} The supply chain includes every interaction between suppliers, manufacturers distributors and customers and includes transportation, scheduling, accounts payable and receivable, material transfers and the exchange of ideas.

During new product development it is necessary to set-up and manage the supply chain that is going to support the existence of the new product. Operations managers need to determine which supply chain strategy works best for their specific operation. One of many suppliers, which focus on the supplier responding to the demands and specifications of a "request for quotation" that usually, goes to the lowest bidder. A many supplier strategy allows suppliers to aggressively compete with one another and relationships are not the primary goal of this strategy. This approach requires the supplier to maintain responsibility for maintaining the needed technology, expertise, forecasting abilities, cost, quality and delivery competencies.

Conversely, a strategy that uses a few suppliers implies that the customer is looking for a long-term relationship rather than a short-term advantage like low cost. Suppliers taking part in a few-supplier strategy are often more willing to participate in a JIT program as well as, provide assistance in design innovation and expertise.

The final supply chain strategy is vertical integration or "developing the ability to produce goods or services previously purchased or actually buying a supplier or a distributor." \{Heizer and Render, pp. 418\} Vertical integration works best when, "an organization has large market share or the management talent to operate an acquired vendor successfully." \{Buzzell, pp. 92-102\} Vertical Integration is not likely in the development of a new product unless done so by a company with the resources large enough to undertake such a risk.

\section{Inventory Management}

Inventory management can serve several functions within a corporation. It can be used to separate various production processes, protect against fluctuations in demand, utilize quantity discounts and hedge against inflation. However, during new product introduction, knowing how inventory items will be classified and how accurate inventory records must be, is more important than inventory management once the product is in full production.

In addition to determining classification and record keeping it is important that a company determines exactly what forms of inventory will be carried through the product life cycle. In a manufacturing process raw material, WIP, MRO and finished goods inventory are going to be a necessity.

\section{Scheduling}

Top management is usually responsible for the long range capacity and strategic issues like, facility location and expansion, new product development, research funding and investment. The policies set forth by upper management are usually done so over a period of several years. Intermediate range planning is usually handled by the operations managers and includes sales planning, production planning, production budgeting, analyzing operating plans, etc. Short-range plans like job assignments, ordering, job scheduling, dispatching, overtime and part-time help are the responsibility of operations managers, supervisors and foreman.

\section{Maintenance}

The final OM strategy decision that has the least effect on new product development is maintenance and reliability. "Maintenance includes all activities involved in keeping a system's equipment in working order and reliability is the probability that a machine part or product will function properly for a specified time under a stated condition." \{Heizer and Render, pp. 622\} While these issues are going to be unknown at the start they should have some bearing on the initial forecasting for the new product. Once the variables are worked out, implementing and improving preventative maintenance and increasing the repair capabilities and speed should be one of the primary objectives of the operations management team. A good maintenance and reliability strategy leads to reduced 
inventory, improved quality, improved capacity, better reputation for quality, continuous improvement and reduced variability.

Once all ten OM decisions have been made, monitored and tested a new product is welcomed to the market that demanded it. The finance team will price it competitively, the marketing people will attempt to make the customers feel they need it and the sales people will do their best to sell it to them. However, it will be the hundreds; possibly thousands of steps that those on the operations end performed that have brought the product to life.

\section{E-COMMERCE}

Our product is at the forefront of technology; therefore, our sales and purchasing techniques should also be progressive. E-procurement has brought purchasing to a new level. The modern ways of purchasing and order releases is communicated via the Internet or through an online catalog. We have chosen to provide an online catalog to our customers in order to provide technology-minded customers what they want. This catalog will allow us to take orders 24 hours a day. Also our efficiencies will increase as we reduce our costs providing our customers an online way to shop.

There has been a steady increase in the use of e-procurement, especially in the B2B realm. A study performed by the research firms Forrester Research and the Institute for Supply Management has shown that largevolume (over $\$ 100$ million) buyers are most likely to use the Internet with $49.4 \%$ viewing it as very important or critical. (Gonsalves)

In order to begin selling on the Internet, our company must have a clear objective and goal. It is essential that we have a mission statement for this venture, which will be separate from the mission of our core company. We should also have a clear business plan for this operation, illustrating our plan with long-term and short-term goals. Staffing will have to be addressed because maintenance of an e-commerce site will require technical support. We can choose to maintain the site internally or outsource it to another company.

Several advantages of e-procurement can be noted: it helps eliminate human error, it can help reduce procurement costs, it allows companies to secure better prices and contract terms, and critical data is stored in each transaction, allowing companies to track their progress. It also lowers inventory and facility costs. Along with several benefits, we must be careful to pay attention to several issues that may arise with e-procurement. Eprocurement should not be used as a stand-alone method for purchasing, it is an enhancement to our services. The customer should be provided with several options for accessing our sales department.

Strategic sourcing can be an added benefit of e-procurement. By setting up the purchasing information for our customer, including part numbers, we can make the process so simple and quick that they refuse to buy anywhere else. The benefit to the buyer is allowing them to consolidate their vendors as well as being able to order quickly by part number directly from a site customized to their needs. They can enter our site by giving their username and password. From that point on, the site would list their part numbers, order history including purchasing totals for the year, and be able to track their current orders. Orders can then be printed or can be accessed through our site 24 hours a day. The customer's MRP system can also be coordinated with our catalog, allowing the customer to order based on their manufacturing schedule. This eliminates faxing, phoning and filing between our company and the buyer. It also provides for a more effective just-in-time delivery system. Most importantly e-procurement for the buyer removes them from the transactional duties of purchasing and allows them to focus on more value-added services for their company.

For those buyers not interested in strategic sourcing or for one-time buyers, our catalog can offer an array of products with pictures, descriptions, and comparisons. They can enjoy the ease of shopping online without the hassle of an aggressive salesperson. They can also apply for credit on our site. If the one-time-buyer becomes a repeat buyer, they can have their information stored in their account for easy reordering. 
There are several ways to increase our exposure on the Internet such as registering on search engines such as Yahoo, Lycos, Google, and Excite. We can use e-mail marketing, paying for e-mail addresses of our target market through a marketing research firm. We can also pay for banner advertising on sites commonly visited by our target market. Our website will also include a feature to sign up for our monthly ezine with updates on our newest products. Due to the nature of the electronics industry, our product line renews itself often.

\section{How It Works}

The customer goes into their ERP or MRP system and creates a batch file, which then connects to our network, where it is converted into ANSI, and we receive it from that point. The customer just inputs it into his own system and the material arrives on the customer's floor without any further work on the customer's end. It can eliminate the need for double entry, and essentially reduce human error. Once the orders are placed, our production schedule is adjusted accordingly. After our customers have entered their orders, our suppliers can see our production schedule online so that they can forecast their own production and maintain on-time delivery.

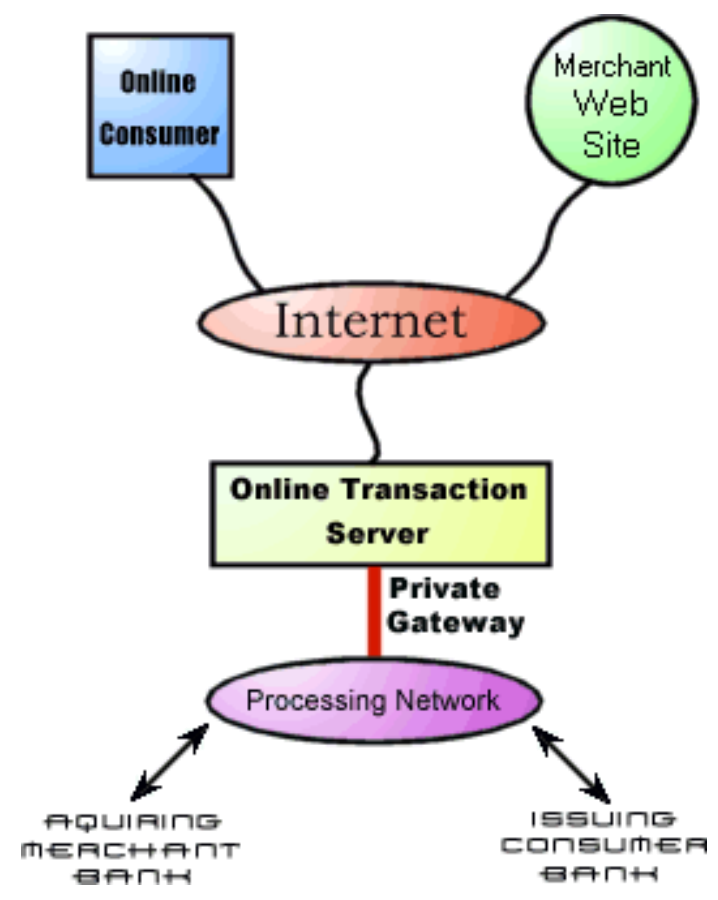

\section{AUTHOR INFORMATION}

Dr. Manna utilizes a pragmatic yet highly motivational and entertaining approach in his classroom instruction and seminars, maintaining a high level of interest while transmitting valuable information with high levels of content. He has published a sales manual on Client Centered Selling for use in the classroom and corporate seminars. His teaching specialty is Professional Selling both at the undergraduate and graduate level. He has been in Greece, teaching marketing and management courses to business executives from the sport-management disciplines. Dr. Manna's primary research interest is on Emotional Intelligence and its effects on productivity and morale in the public and private sectors. His has also conducted research in the areas of Marketing and Supply Chain Management.

He holds his undergraduate degree in Business from Gannon University, an MBA from the University of Cincinnati, and his Ph.D. from the University of Pittsburgh. Dr. Manna is a University Professor and holds the position of Department Head of Marketing in the School of Business at Robert Morris University. 


\section{REFERENCES}

1. Probert, D. R. "The make or buy decision in the context of manufacturing strategy development." Journal of Engineering Manufacture, Vol 207, 1993.

2. Heizer, Jay and B. Render. Operations Management $-7^{\text {th }}$ Edition. Upper Saddle River, NJ: Pearson Education, 2001.

3. Buzzell, Robert. "Is Vertical Integration Profitable?" Harvard Business Review, Jan-Feb 1983.

4. Gonsalves, Antone. "Purchasing Execs See Rise in E-Procurement." InternetWeek, January 2003.

5. http://www.online-commerce.com/tutorial.html 


\section{NOTES}

